\title{
EDUCAÇÃO AMBIENTAL E POPULLARIZAÇÃO DO CONHECIMENTO: PERCEPÇÃO DE ESTUDANTES SOBRE UMA UNIDADE DE CONSERVAÇÃO NA BAHIA
}

\author{
Jéssica Vinhático ${ }^{1}$ \\ Laís Alves ${ }^{2}$ \\ Andrea Karla Almeida dos Santos ${ }^{3}$
}

Resumo: $O$ acesso à informação é fundamental para o desenvolvimento da consciência ambiental crítica. Nesse sentido, esta pesquisa buscou realizar o levantamento da quantidade de estudos sobre o Parque Municipal da Serra do Periperi, bem como, diagnosticar o alcance da popularização das informações desses estudos na população escolar/universitária de Vitória da Conquista. Os dados foram levantados através de questionário aplicado a alunos de três escolas e uma unidade de ensino superior, entre outubro e novembro de 2018. O estudo evidenciou um desequilíbrio entre a quantidade de informações disponíveis e o nível de conhecimento do público estudado. A inexistência de um programa sistemático de Educação Ambiental possivelmente contribui para esse cenário.

Palavras-chave: Percepção Ambiental; Popularização da Ciência; Parque Municipal da Serra do Periperi.

Abstract: Access to information is necessary for the development of environmental critical awareness. Seeking to verify if the information available from the studies carried out on the Serra do Periperi Municipal Park are known by the population in Vitória da Conquista, this research aimed to conduct a survey of materials and work on the subject, as well as, from semi-structured interviews, diagnose the popularization of information about the Park. The study clearly demonstrated a balance between the amount of information available and the level of knowledge of the public studied. Probably the inexistence of a systematic program of Environmental Education contributes to this scenario.

Keywords: Environmental Perception; Popularization of Science; Parque Municipal da Serra do Periperi.

\footnotetext{
${ }^{1}$ Universidade Estadual de Santa Cruz. jeelvinhatico@gmail.com, Link para o Lattes: http://lattes.cnpq.br/8217527046406237

${ }^{2}$ Universidade do Estado do Rio de Janeiro. allveslais@gmail.com,

Link para o Lattes: http://lattes.cnpq.br/9180410017263912

${ }^{3}$ Universidade Federal da Bahia. andreakarlaufba@gmail.com,

Link para o Lattes: http://lattes.cnpq.br/6358588688610804
} 


\section{Introdução}

O conhecimento científico é cada vez mais necessário e de suma importância na sociedade atual, podendo auxiliar na formação de opiniões e decisões de cada indivíduo, e quando isso acontece o conhecimento referido é produto da popularização da ciência (MUELLER, 2002).

A educação do cidadão como um todo, e, consequentemente a Educação Ambiental do indivíduo, envolve sua percepção que é estimulada pelos meios de comunicação. Já a popularização, por sua vez, está envolvida nesse processo e contribui para essa percepção (JACOBI, 2003; FERNANDES, 2010; BARBOSA, 2004). Dentro do contexto da Educação Ambiental, podemos destacar a sua importância na preservação da biodiversidade e consequentemente do conhecimento acerca das Unidades de Conservação (UC) (SANTOS, et al., 2013).

A criação de Unidades de Conservação é uma tentativa de garantir que a biodiversidade dos diferentes locais e regiões seja conhecida e mantida. E um fenômeno que ocorre em todo o país, nas esferas municipais, estaduais e federais como um dos desdobramentos da Convenção Sobre Diversidade Biológica (CDB) e a consulta pública deve preceder a criação de uma UC, bem como neste momento todo o esclarecimento necessário deve ser fornecido a população (BRASIL, 2002; BAHIA, 2017).

O Parque Municipal da Serra do Periperi (PMSP) é uma UC de proteção integral, onde é admitido apenas o uso indireto dos seus recursos naturais (Art. $7^{\circ}$. $\S 1^{\circ}$., da Lei do SNUC), tendo "como objetivo básico a preservação de ecossistemas naturais de grande relevância ecológica e beleza cênica, possibilitando a realização de pesquisas científicas e o desenvolvimento de atividades de educação e interpretação ambiental, de recreação em contato com a natureza e de turismo ecológico" (caput do Art. 11). O Parque foi criado há pouco mais de duas décadas com o propósito principal de dirimir a degradação ambiental causada principalmente pela ação antrópica, numa área com riqueza biológica notória (Decreto no 9.480/99). Essa é uma unidade de grande relevância para a manutenção da biodiversidade da região por possuir nascentes e minadouros que são importantes para os recursos hídricos, além de conter a Reserva Florestal do Poço Escuro, a qual possui grande diversidade da fauna e flora regional, características que levaram ao decreto de $n^{\circ}$ 9.480/99 de criação do Parque (VITÓRIA DA CONQUISTA, 2017).

Atualmente, os impactos ambientais e socioeconômicos no Parque são bastante evidentes, decorrentes da inexistência de ações efetivas dentro de planejamento ambiental que garanta a sustentabilidade dos recursos naturais. A expansão desordenada e rápida da ocupação, acentuada principalmente com a construção do Anel Viário Jadiel Matos, tem proporcionado remoção da vegetação nativa, para dar lugar a habitações, sem considerar a aptidão das terras e a adoção de práticas de manejo e conservação de solo, além da destruição de habitats, que acelerou os processos erosivos (AMARAL, 2012; ROCHA, 2008; SILVA, 2013).

revista brasileira educação ambiental 
Até o momento, a infraestrutura da qual o Parque é dotado está limitada aos serviços realizados na fiscalização, recuperação de animais silvestres vítimas do tráfico, produção de mudas de espécies nativas e exóticas utilizadas na revegetação do parque e na arborização urbana, sendo estas edificações utilizadas exclusivamente pelos servidores envolvidos nos trabalhos e um módulo de Educação Ambiental que recebe visitantes (VITÓRIA DA CONQUISTA, 2017).

De acordo com Córdula et al. (2015), desde a Conferência de Tiblisi em 1977, com a criação do Programa Internacional de Educação Ambiental, a sensibilização vem sendo usada como abordagem global para transformar valores e atitudes dos seres humanos frente aos problemas ambientais crescentes. Nesse contexto, a preservação do meio ambiente é essencial na busca de melhorar a qualidade de vida para a população e, a educação escolar sobre a preservação ambiental contribui para o pensar dos estudantes em qualquer nível de ensino sobre suas atitudes em relação ao meio ambiente (FERREIRA; VIANA JÚNIOR, 2016).

O ensino de Educação Ambiental nas escolas pode então contribuir para que os alunos tenham uma formação voltada para a sensibilização ambiental e abordando aspectos sobre a importância do meio ambiente para a vida, como também a necessidade de conservar e preservar (XAVIER et al., 2016).

Apesar de duas décadas de criação do Parque, percebe-se a falta de conhecimento de muitos a respeito do mesmo. Diante disso, esse trabalho justifica-se por mostrar a importância da popularização das pesquisas e sua utilização como forma eficiente de transmitir informações a população, fazendo então com que essa população se torne parceira na busca pela conservação de reservas como o Parque Municipal da Serra do Periperi.

Considerando que o Parque já foi objeto de muitas pesquisas e verificando que diversas vezes o conhecimento ou as informações oriundas destes estudos não são difundidas para a população (observações pessoais) esse trabalho teve como objetivo realizar o levantamento da quantidade de estudos ou pesquisas que trabalharam com temas sobre o Parque, bem como realizar uma análise para diagnosticar o alcance da popularização das informações gerais desses estudos ao conhecimento na população escolar/universitária de Vitória da Conquista.

\section{Metodologia}

Trata-se de uma pesquisa descritiva, quantitativa e exploratória, realizada em duas etapas. No primeiro momento foi realizado um levantamento bibliográfico e no segundo uma aplicação de questionários para estabelecer um diagnóstico sobre a Educação Ambiental de uma parcela estudantil de Vitória da Conquista-BA. 


\section{Levantamento de dados}

Seguindo a proposta de Gil (2002) a coleta de dados foi realizada nas seguintes etapas: foram utilizadas fontes de vários tipos, sem critérios de exclusão, pois devido ao tema ser mais restrito cada informação encontrada poderia vir a ser de grande valia. Utilizou-se de base de dados como: Scielo e Google Acadêmico, com as palavras-chave: serra do Periperi, Vitória da Conquista, Melocactus. Foi realizada ainda uma busca por materiais impressos que não estejam disponíveis na internet em órgãos do município ligados a área do meio ambiente (Secretaria do Meio Ambiente e Ministério Público Estadual), para verificar informações não acadêmicas que pudessem ser úteis ao estudo.

A coleta seguiu a seguinte premissa: a) Leitura Exploratória de todo material encontrado (leitura rápida que permitisse selecionar se era válida ou não para o estudo); b) Leitura Seletiva (leitura aprofundada nas partes de maior interesse); c) Registro das informações encontradas na leitura (título, ano, autor, resultados, conclusões).

\section{Tramitação ética}

O projeto foi submetido, avaliado e a execução da pesquisa foi aprovada pelo Comitê de Ética em Pesquisa com Seres Humanos (CEP - SERES HUMANOS) da IMS/UFBA, sob o número CAAE: 96226318.9.0000.5556.

\section{Caracterização dos locais estudados}

O estudo foi realizado com alunos de três escolas e uma unidade de ensino superior do município de Vitória da Conquista, sudoeste da Bahia, no período de outubro a novembro de 2018 (Figura 1). A primeira escola foi a Monteiro Lobato, de rede particular de ensino, localizada no Bairro Brasil, funcionando nos dois turnos (matutino e vespertino) com alunos de maternal a Ensino Médio. Nessa escola, os entrevistados foram alunos do 9ำ ano (Ensino Fundamental II). A segunda escola foi a Dom Climério, de rede estadual, localizada na Urbis VI, funciona em turno integral com alunos do Ensino Médio, nesse caso, os entrevistados foram alunos do $3^{\circ}$ ano do E.M. A terceira escola foi a Professora Ridalva Correa de Melo, rede municipal, localizada no Bairro Ibirapuera, funciona nos dois turnos (matutino e vespertino) com alunos do Ensino Fundamental I e II. Nessa escola, os entrevistados foram alunos no 9o ano (Ensino Fundamental II). A unidade de ensino superior selecionada foi a Universidade Federal da Bahia - Campus Anísio Teixeira, localizada no bairro Candeias, funciona em tempo integral, com 6 cursos de graduação. 


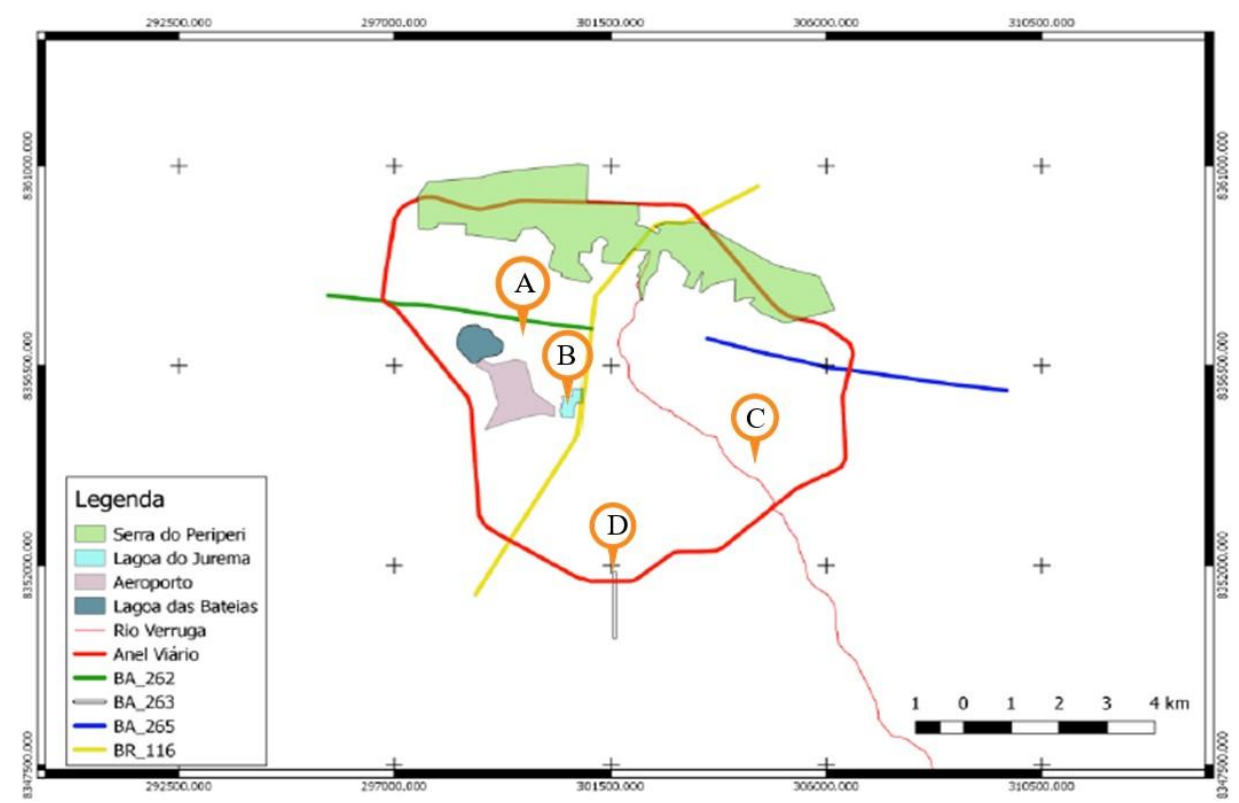

Figura 1: Localização das escolas participantes da pesquisa em relação ao Parque (em verde): A) Escola Municipal Professora Ridalva; B) Escola Monteiro Lobato; C) UFBA e D) Escola Estadual Dom Climério. Fonte: Vitória da Conquista (2017).

\section{Caracterização Amostral}

Para analisar o alcance das produções sobre o Parque, bem como referências da população estudante sobre o assunto, o presente estudo abrangeu 415 indivíduos, agrupados em: a) graduandos da Universidade Federal da Bahia - Campus Anísio Teixeira ( $n=220)$; b) alunos do 9o ano da Escola Monteiro Lobato $(n=68) ; c)$ alunos da $3^{\text {a }}$ série do Ensino Médio da Escola Estadual Dom Climério ( $\mathrm{n}=80)$; d) alunos do 9 o ano da Escola Municipal Professora Ridalva $(n=47)$. Escolheu-se trabalhar com alunos de $9^{\circ}$ ano e $3^{\circ}$ ano por se tratar das séries finais do Ensino Fundamental II e Ensino Médio, sendo fases de transição, em que os alunos já dominam a escrita, são curiosos e já trazem consigo um conhecimento sobre o ambiente. $O$ dimensionamento amostral de populações superior a 100 indivíduos foi feito adotando nível de confiança de $95 \%$ e erro máximo de estimativa de $5 \%$ em expressão matemática descrita abaixo.

$$
n=\frac{N \cdot z^{2} \cdot p \cdot(1-p)}{z^{2} \cdot p \cdot(1-p)+\varepsilon^{2} \cdot(N-1)} \quad \begin{aligned}
& \mathrm{n}=\text { tamanho da amostra, } \\
& \mathrm{N}=\text { tamanho do universo (população total), } \\
& \mathrm{z}=\text { desvio médio para nível de confiança, } \\
& \mathrm{e}=\text { margem de erro, } \\
& \mathrm{p}=\text { proporção. }
\end{aligned}
$$

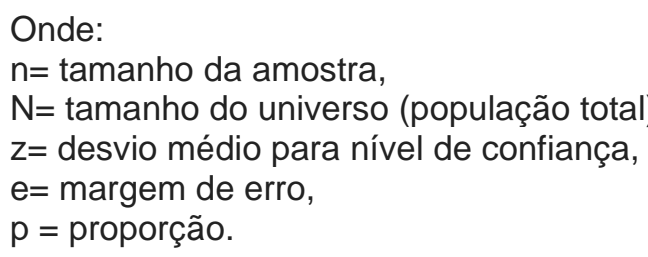

\section{Resolução dos questionários}

Um tipo de questionário de mesma composição foi dirigido aos 4 diferentes tipos de grupos, com participantes voluntários. Em seguida, tratados como $\mathrm{A}, \mathrm{B}, \mathrm{C}$ e $\mathrm{D}$, os questionários, constituídos de perguntas do tipo simples, buscavam investigar se algumas informações básicas das pesquisas realizadas 
sobre o Parque Municipal da Serra do Periperi fazem parte do conhecimento que as pessoas têm sobre a unidade de conservação. As perguntas buscaram relacionar palavras-chave sobre a localização do Parque e espécies que lá ocorrem, bem como a fonte da informação do entrevistado. Além disso foi questionado se existe interesse do público para atuar em projetos de relacionados ao Parque. $O$ questionário contou com um total de 12 questões semiestruturadas que duraram cerca de 5 a 10 minutos para serem respondidas. (Anexo 1)

Os questionários foram aplicados presencialmente e preenchidos manualmente pelos voluntários, no período de outubro a novembro de 2018. em locais específicos onde se encontravam os entrevistados, a fim de minimizar qualquer desconforto provenientes de uma locomoção. Seguindo as orientações e preceitos éticos na pesquisa, apenas os dados coletados mediante assinatura do Termo de Consentimento Livre e Esclarecido - TCLE (para os de maioridade) e o Termo de Assentimento - TA (para os de menor idade) foram validados e utilizados. De posse dos dados obtidos pela pesquisa, fez-se a interpretação e identificação das respostas mais abordadas. Os dados dessa pesquisa foram apresentados por estatística descritiva.

\section{Resultados}

\section{Artigos, trabalhos científicos em Periódicos e notícias}

Utilizando a pesquisa de busca em bases de dados acadêmicos com as palavras-chave: "Serra do Periperi, Melocactus, Vitória da Conquista", foram encontrados 520 trabalhos publicados sobre o Parque, sendo 516 do Google Acadêmico e 4 da base Capes. Esses trabalhos são de diferentes áreas de conhecimento como: Ciências Biológicas (82 artigos, 49 monografias e 20 dissertações/teses), Geografia (40 artigos, 27 monografias e 25 dissertações/teses), Agronomia (32 artigos, 22 monografias e 15 dissertações/teses), Pedagogia (20 artigos, 25 monografias e 10 dissertações/teses) e Engenharia Ambiental (93 artigos, 50 monografias e 10 dissertações/teses). Houve ainda a pesquisa de buscas no Google usando como palavra-chave: "Parque Municipal da Serra do Periperi", sem nenhum critério de exclusão. Obtendo um resultado de 96 notícias em sites e blogs e mais de 34.000 respostas para essa busca no geral, sendo basicamente predominante nesses sites imagens e vídeos sobre a Serra do Periperi.

\section{Publicações impressas com ênfase na Educação Ambiental}

A maior parte das publicações impressas não acadêmicas está relacionada com materiais voltados para a Educação Ambiental. Foram encontradas cerca de 30 produções distintas, oriundas de projetos realizados em parceria entre a Prefeitura municipal, instituições de ensino do município e Ministério Público, para produção de revistas ambientais, cartilhas ambientais, cartazes e folhetos informativos (Tabela 1). Vale destacar que a maior parte dos 
materiais com esse perfil de Educação Ambiental ou popularização do conhecimento foi produzido e publicado esporadicamente, em função de algum evento ou projeto pontual, como exemplo a cartilha ambiental produzida pela ViaBahia. Como exceção, existem as revistas do Projeto Ecokids e Ecoteens (Figura 2), criadas em 2013, com edições publicadas de 3 a 5 vezes no ano com diferentes escolas (públicas e privadas) que são convidadas a participar da elaboração da revista, com temas relacionados ao meio ambiente na região de Vitória da Conquista e outros municípios vizinhos. Esse material é custeado pelo Fundo de Meio Ambiente disponibilizado pelo Ministério Público. Importante ressaltar que alguns dos materiais estão disponíveis via impressa e online no site do Ministério Público da Bahia ${ }^{4}$.

Tabela 1: Exemplos de materiais publicados, voltados para a Educação Ambiental e disponibilizados pela Secretaria Municipal de Meio Ambiente para visitantes. Na última coluna está especificado qual o setor em que o material pode ser consultado ou retirado.

\begin{tabular}{rlll}
\hline Material & Tipo & Onde foi consultado/retirado & $\begin{array}{c}\text { Regularidade das } \\
\text { publicações }\end{array}$ \\
\hline $\begin{array}{rll}\text { Revista Turma da } \\
\text { Sarú }\end{array}$ & Impressa & $\begin{array}{l}\text { Módulo de Educação Ambiental } \\
\text { (MEA) }\end{array}$ & Irregular \\
\hline $\begin{array}{r}\text { Revista Ecokids } \\
\text { Ecoteens }\end{array}$ & Impressa e & $\begin{array}{l}\text { MEA e site do Ministério Público da } \\
\text { Bahia }\end{array}$ & Regular (Mensal) \\
\hline $\begin{array}{rlll}\text { Cartilha Ambiental } \\
\text { ViaBahia }\end{array}$ & Impressa & MEA & Irregular \\
\hline Cartilha Embasa & Impressa e & MEA e site do Ministério Público da & Irregular \\
& online & Bahia & \\
\hline EcoGibi & Impressa & MEA e Ministério Público da Bahia & Regular (Anual) \\
\hline & & Fonte: Autoria Própria. &
\end{tabular}
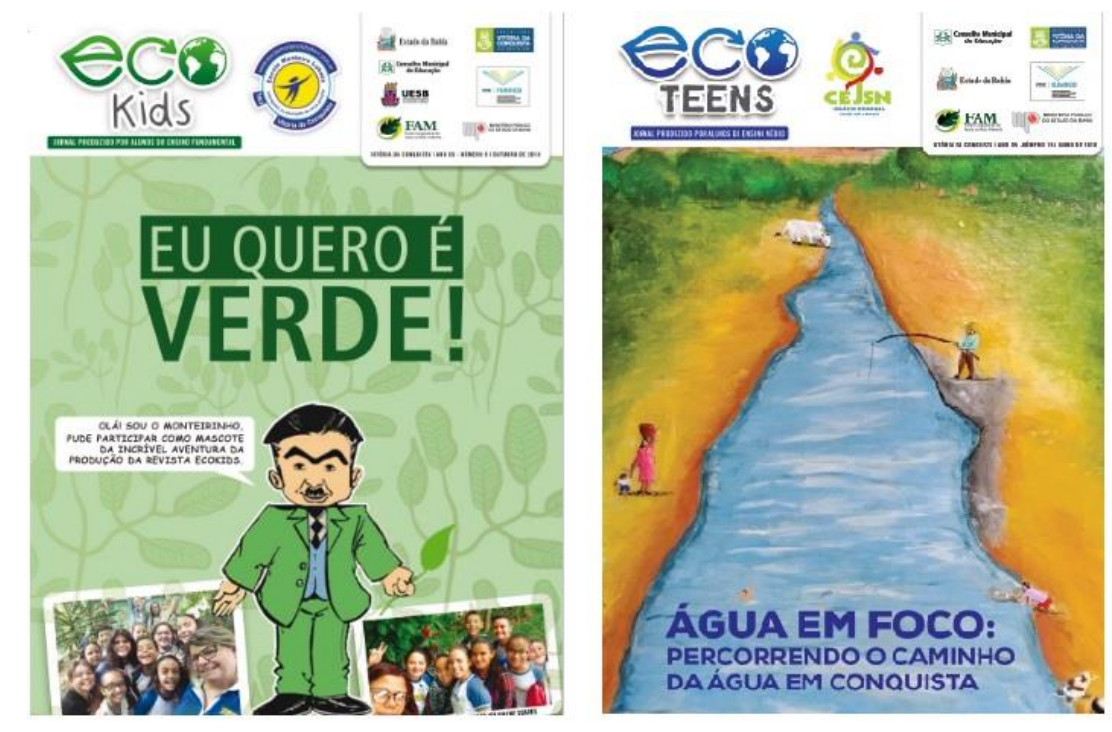

Figura 2: Capa de revistas produzidas pelos alunos das escolas públicas e privadas de Vitória da Conquista dos projetos Ecokids e Ecoteens do ano de 2018. Fonte: Arquivo pessoal.

\section{${ }^{4}$ Eco Kids Eco Teens (mpba.mp.br)}




\section{Questionários}

Após a aplicação dos questionários, obteve-se a quantidade total 415 pessoas entrevistadas, nas quatro instituições de ensino selecionadas, com idade variando de 14 a 35 anos. Abaixo, as respostas foram agrupadas por tópicos para facilitar a explanação ou apresentação dos dados.

\section{Tempo de residência em Vitória da Conquista e fonte de informações que conhecem sobre o Parque}

No tocante a este tópico foi verificado que dentre os alunos das escolas $80 \%$ dos entrevistados residem há mais de 10 anos, já na Universidade esse resultado foi contrastante, apenas 38\% residem há mais de 10 anos e $40 \%$ residem de 1 a 3 anos na cidade, o que já era esperado visto que o perfil da universidade inclui uma grande quantidade de alunos oriunda de outras cidades. Independentemente do tempo de residência, mais de $70 \%$ do total de entrevistados já ouviu falar sobre o Parque (Figura 3) e que as informações chegaram principalmente pela TV $(28 \%)$, escola $(25 \%)$ e internet $(17 \%)$.

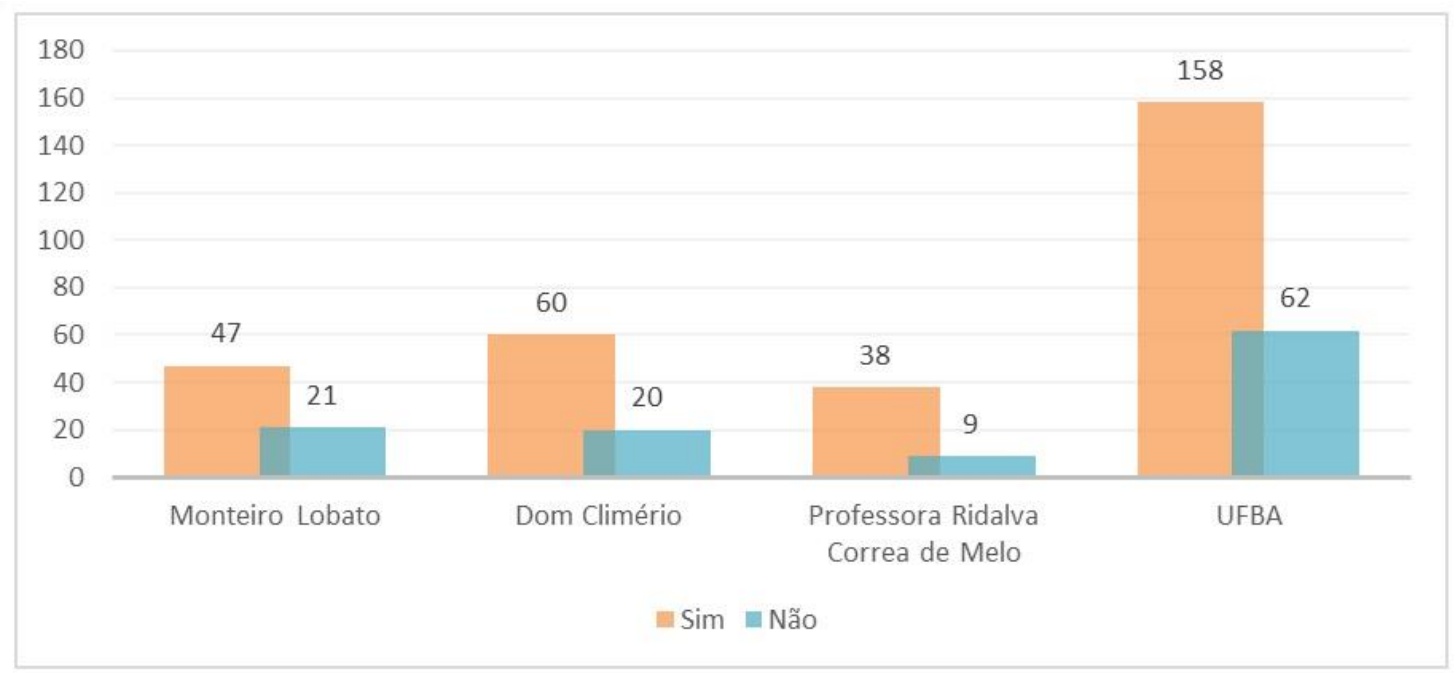

Figura 3: Total de alunos de cada Instituição que já ouviu falar sobre o Parque Municipal da Serra do Periperi. Fonte: Autoria própria.

Destaca-se aqui que, apesar da escola ter sido a segunda fonte mais citada onde os entrevistados já tiveram contato com as informações, a grande maioria respondeu que nunca realizou trabalho relacionado ao Parque, e quando a resposta era positiva, foi dito que ocorreu apenas uma vez essa atividade (Figura 4). Foi questionado ao público entrevistado se eles já haviam visitado a Unidade de Conservação e a maioria (80\%) afirmou que nunca visitou nenhum local do Parque (Figura 5). 


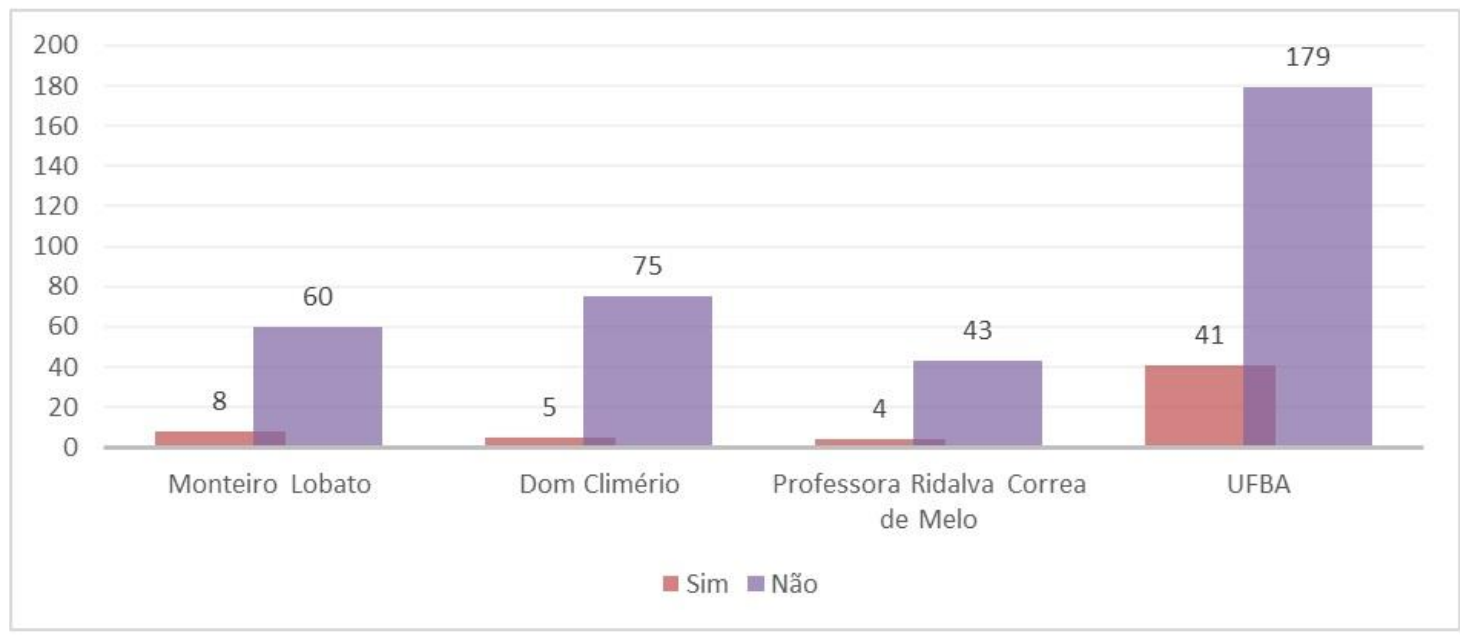

Figura 4: Total de alunos de cada instituição que realizaram algum trabalho relacionado ao Parque Municipal da Serra do Periperi. Fonte: Autoria própria.

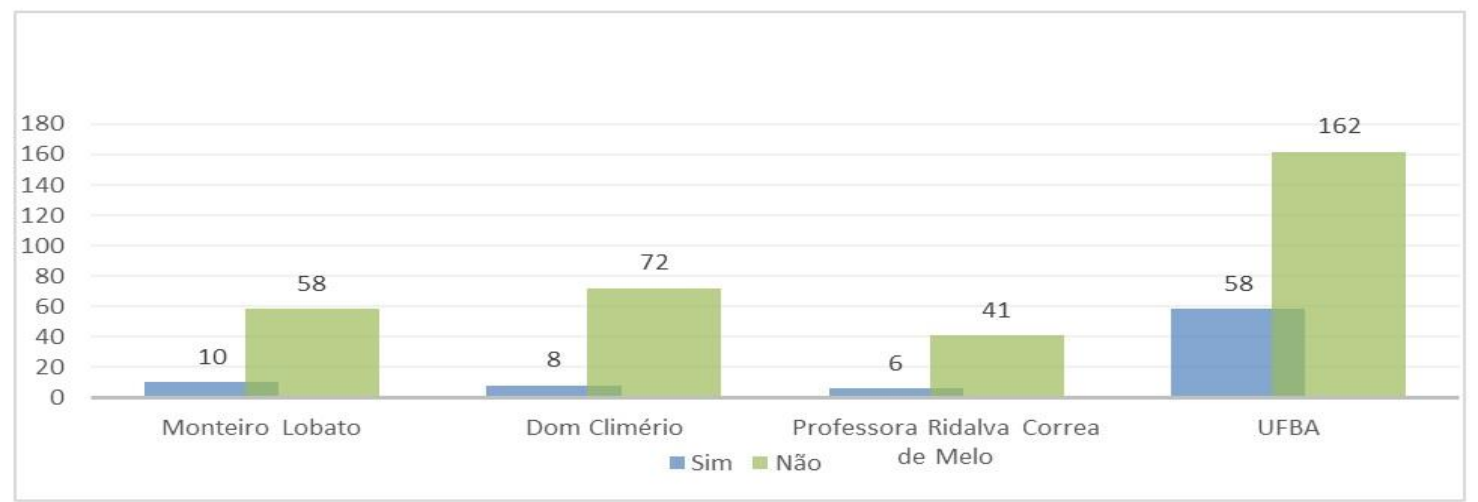

Figura 5: Total de alunos de cada Instituição que já visitaram o Parque Municipal da Serra do Periperi. Fonte: Autoria própria.

\section{Educação Ambiental sobre o Parque: quais as fontes e referências que 0 nosso público tem?}

Foram lançadas algumas questões aos entrevistados para verificar se eles reconheciam a ação de entidades técnico-científicas sobre o Parque e quais as impressões que teriam ficado no público-alvo. Assim, foi perguntado se eles já foram abordados por órgãos responsáveis ou grupos de pesquisa e mais de $90 \%$ afirmaram que nunca foram abordados por ninguém para conversas sobre o assunto.

Entretanto, mais de $95 \%$ dos alunos consideram que conhecer informações sobre o Parque ajuda a proteger a natureza da nossa cidade e está diretamente relacionado a Educação Ambiental. Do mesmo modo, quando questionados se gostariam de participar de algum projeto de proteção ao Parque, mais de $20 \%$ responderam que sim, $70 \%$ talvez, dependendo do projeto, e apenas $10 \%$ responderam que não teria interesse (Figura 6 ). 


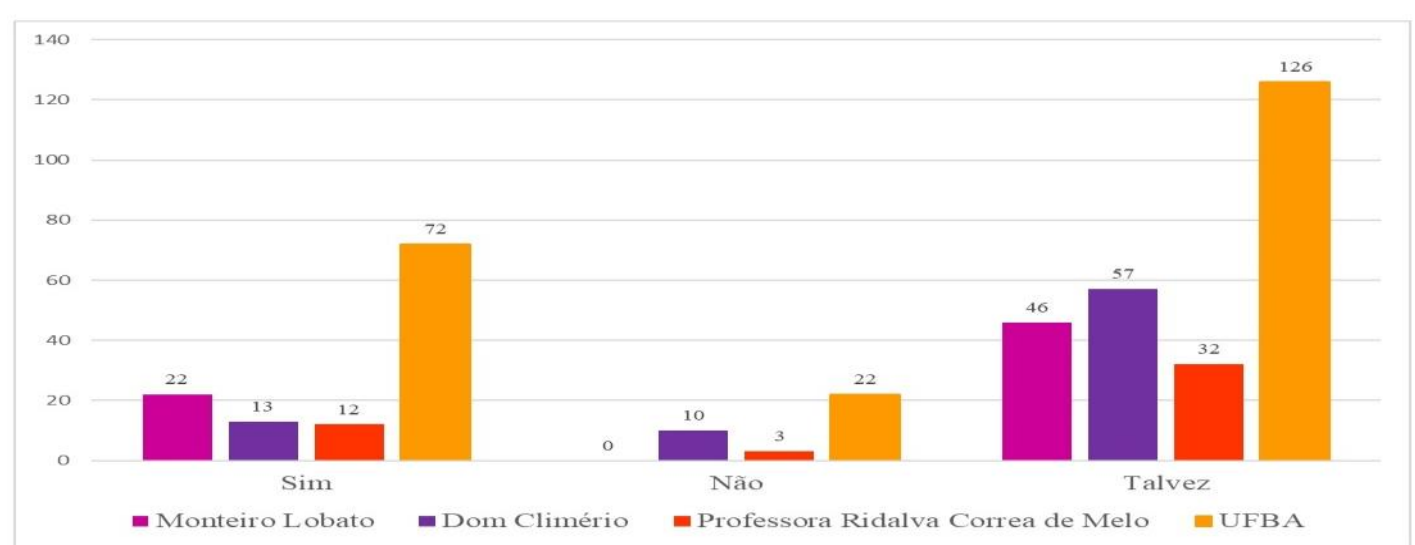

Figura 6: Gráfico comparativo dos alunos que tem interesse em participar de algum projeto no Parque. Fonte: Autoria própria.

Em relação ao conhecimento de cada um acerca do Parque, foi solicitado que os entrevistados marcassem no questionário palavras que considerassem diretamente relacionadas ao assunto, "Poço Escuro" foi o termo que mais apareceu, citado por mais de $70 \%$ do total de entrevistas (Figura 7). Depois de "Poço Escuro", a palavra mais citada foi "Cristo", seguido de Caatinga e Rio Verruga. De fato, estas palavras são diretamente relacionadas ao Parque. Muito nos chamou atenção o fato de que as palavras: "Anel de Contorno/Anel viário" (6\%), Melocactus (8\%) e CETAS (5\%) são reconhecidas por menos de $9 \%$ dos entrevistados como diretamente ligadas ao Parque. Por exemplo, o anel de contorno da cidade atravessa os limites do Parque (localização), o Melocactus conoideus Buining \& Bredero foi uma das espécies que motivou a criação do Parque por ser endêmica e ameaçada de extinção e o CETAS é o Centro de Triagem de Animais Selvagens, localizado nos limites do Parque e frequentemente é noticiado na TV e blogs da Internet por conta das apreensões de muitos animais principalmente aves, realizadas pelo IBAMA e Polícia Militar ou Rodoviária Federal.

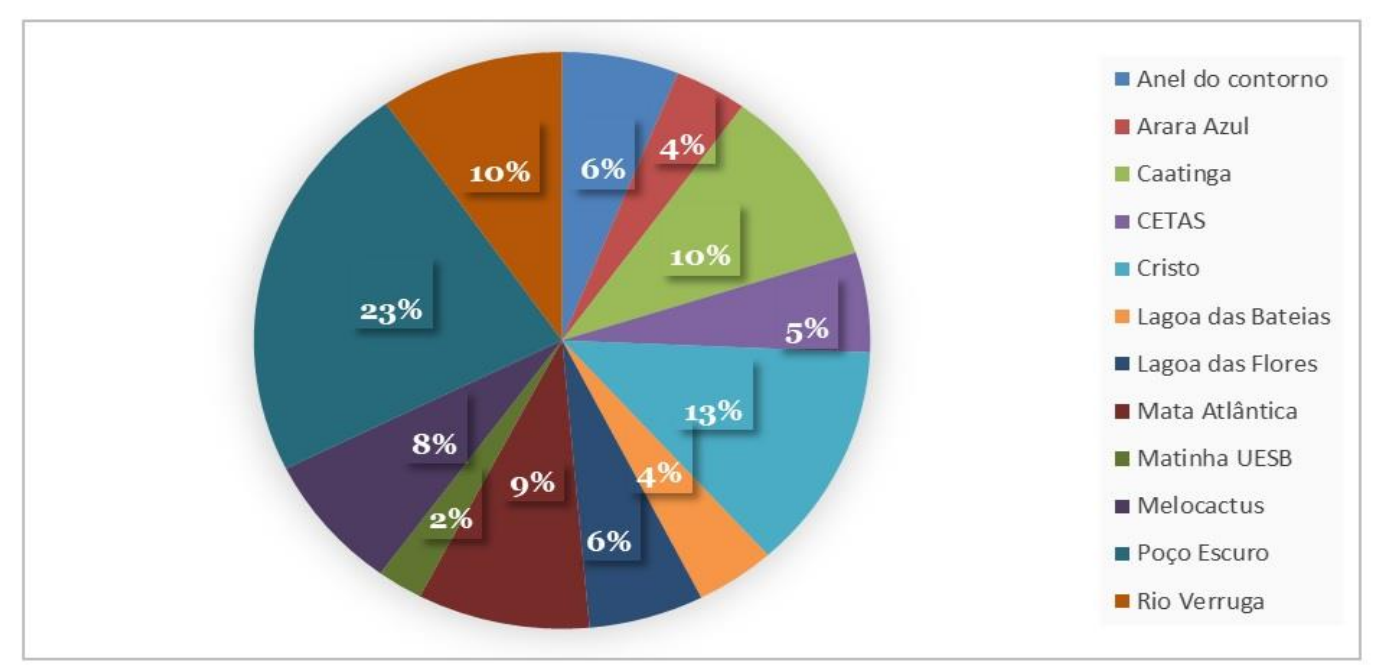

Figura 7: Porcentagem geral das palavras consideradas pelos entrevistados.

Fonte: Autoria própria. 
Para finalizar, os entrevistados foram questionados se já ouviram falar sobre problemas relacionados ao Parque, $60 \%$ disseram não ter ouvido falar, $32 \%$ responderam que já ouviram algo, mas não lembrava o que era, e $9 \%$ ouviram falar sobre problemas como: extinção, invasões, poluição do rio Verruga e queimadas. Quando questionados sobre se sabiam se existia alguma espécie em risco de extinção no Parque mais de $80 \%$ dos entrevistados disseram que sim, porém não sabem qual é a espécie em risco, o que foi evidenciado nas palavras citadas, visto que o "Melocactus" foi pouco citado nas palavras relacionadas ao Parque.

\section{Discussão}

A popularização do conhecimento, como já dito, é a transposição de ideias contidas nos textos científicos para os meios de comunicação e linguagem popular (MUELLER, 2002). Na ciência, a popularização apresenta-se como norteadora de iniciativas que buscam a aproximação e a construção do diálogo entre ciência e público (SOUSA, 2019). A ciência e a tecnologia são patrimônios da humanidade, e a popularização é uma ação de grande importância e necessária atualmente na sociedade. No âmbito ambiental ela deve caminhar junto com a educação, em uma relação estreita de dependência de um pelo outro.

A Educação Ambiental (EA) atua como um importante espaço de mediação da relação da sociedade com natureza. Esse processo de educação em uma unidade de conservação é imprescindível para a sensibilização da sociedade como um todo. De acordo com Santos et al. (2013) a população acaba por ameaçar a proteção da biodiversidade por não ter conhecimento de como poderiam proteger o ambiente em que vivem, portanto, a EA assume um papel imprescindível, pois ela sensibiliza e acrescenta às comunidades novos hábitos ou mudanças de atividades para a promoção da conservação ecológica das Unidades de Conservação. Segundo Frey (2001), a intervenção do estado como facilitador do processo, estimula a participação das comunidades e fortalece a consciência ecológica.

Após a análise dos dados dessa pesquisa, foi possível identificar alguns aspectos sobre o conhecimento e a percepção ambiental dos alunos entrevistados sobre o Parque Municipal da Serra do Periperi. A vontade de realizar este trabalho surgiu exatamente porque o grupo de pesquisa percebia em conversas que muitas pessoas na cidade de Vitória da Conquista não conheciam informações sobre o Parque, e a hipótese inicialmente, era de que isso acontecia porque não existia material suficiente sobre o Parque que pudesse ser popularizado e distribuído para a população. No entanto, após a pesquisa e revisão bibliográfica foi possível perceber que existem grandes quantidades de materiais tanto de cunho técnico-científico como de linguagem simples para a população, e ainda disponíveis em várias plataformas.

O que se pode afirmar é que, apesar da quantidade grande de materiais sobre diversos assuntos ligados ao Parque, falta a popularização efetiva do 
conhecimento gerado ou a difusão das informações de forma eficiente para a população. Quando foi escolhido o público estudantil, acreditava-se que este perfil seria importante porque normalmente é um grupo que está inserido em várias questões relacionadas ao ensino e a educação, e que está em constante acesso a diversas informações e em construção da consciência ambiental, como afirma Lima (2004):

[...] a escola é um espaço privilegiado para estabelecer conexões e informações, como uma das possibilidades para criar condições e alternativas que estimulem os alunos a terem concepções e posturas cidadãs, cientes de suas responsabilidades e, principalmente, perceberem-se como integrantes do meio ambiente. A educação formal continua sendo um espaço importante para o desenvolvimento de valores $e$ atitudes comprometidas com a sustentabilidade ecológica e social

É possível constatar a falta desse estímulo vindo das instituições de ensino nos resultados das entrevistas, visto que mais de $80 \%$ dos alunos afirmaram nunca ter feito trabalhos sobre o Parque. O que é uma realidade que deve ser mudada, para que se conheça e preserve. Santos (2007), acredita que uma das formas que pode ser usada para o estudo dos problemas relacionados ao meio ambiente é por exemplo, com um componente curricular ou disciplina específica a ser introduzida nos currículos das Escolas, podendo alcançar a mudança de comportamento dos alunos, tornando assim, eles influentes na defesa do meio ambiente para que se tornem equilibrados e saudáveis ecologicamente. Na visão de Guimarães (1995), o Ensino Médio, por exemplo, tem visado apenas o vestibular (e mais recentemente o ENEM) e se esquece da formação de pessoas que pensem de forma crítica, que vejam o mundo e considere o próximo não como um adversário, mas como um cidadão.

$\mathrm{O}$ fato de muitos dos entrevistados residirem na cidade de Vitória da Conquista há mais de 10 anos $(75 \%)$ e nunca terem ouvido falar/visitado o Parque Municipal da Serra do Periperi é preocupante, visto que é uma Unidade de Conservação criada há mais de duas décadas e que está sempre em evidência dos noticiários da cidade. A falta de visitas constantes ao local pode ser explicada pelo fato da maior área do Parque está localizada em bairros mais distantes do centro (no anel de contorno da cidade), as vezes de difícil acesso e que não tem policiamento e segurança suficientes para garantir a visitação frequente. Pádua (2010) afirma:

[...] Mostrar os atributos na natureza, no campo, com certa interpretação ambiental, com certeza fará que pessoas sensíveis aos aspectos estéticos se apaixonem pelos Parques e passem a defendê-los dos destruidores de plantão. 
Segundo Souza et al. (2019) as atividades de campo são instrumentos eficazes para dinamizar as atividades de Educação Ambiental, pois propiciam novas perspectivas de relacionamento entre o homem e a natureza.

Bezerra et al. (2014) comentam a necessidade da implantação de projetos de pesquisas e visitas que ajudem na resolução dos problemas ambientais. Essas questões referentes ao ambiente, sua degradação e formas de protegê-lo devem ser disseminadas em larga escala e integrada por meio do ensino formal e informal para desenvolvimento de medidas para preservar 0 meio ambiente.

De acordo com o público-alvo há claramente o interesse da população em participar efetivamente da proteção da área em relação a projetos ligados a Educação Ambiental da cidade, o que falta então é a efetivação de propostas que possam incluir esse público e popularizar cada vez mais as informações e atividades realizadas podendo assim atingir cada vez mais pessoas. Esse interesse em participar de projetos sobre o Parque está de acordo com uma prática que vem se tornando cada vez mais comum no Brasil: a ciência cidadã! Prática que pode ser entendida como a participação de amadores, voluntários e entusiastas em projetos científicos e tem sido um meio de engajar as populações locais em iniciativas de conservação da biodiversidade (COMANDULLI et al., 2016).

Os programas de ciência cidadã são frequentemente utilizados para proporcionar ao público em geral conhecimentos sobre conservação, ciência e para desenvolver habilidades de pensamento científico (Jordan et al. 2011).

São várias as iniciativas já em andamento aqui no Brasil, como podem ser consultadas no site do SIBBR (Sistema de Informação sobre a Biodiversidade Brasileira), e como enfatizam os especialistas no tema a grande vantagem da ciência cidadã é que qualquer pessoa de qualquer idade, com interesse, curiosidade e responsabilidade em passar os dados corretos pode participar (DICKINSON; BONNEY, 2012).

O envolvimento dos jovens e crianças na produção das revistas do projeto Ecokids e Ecoteens refletem bem esse entendimento, o grupo que se envolve e produz material de qualidade com informações relevantes para auxiliar na formação de novos educadores e de uma consciência ambiental, porém a maioria do material não é veiculado de forma efetiva e está retida dentro de órgãos da prefeitura quando poderiam estar circulando pela cidade e o consumo ser mais incentivado nas redes sociais ou mídias online, já que hoje em dia a população se utiliza muito da internet.

Ivanissevich (2009) acredita que um cidadão bem-informado é capaz de se orientar e até auxiliar nos rumos da ciência, e os jornalistas científicos e pesquisadores têm papel fundamental nesse aspecto. Apresentar as ideias e informações de forma clara e objetiva torna a popularização menos complexa e de fácil alcance. 
A falta do conhecimento sobre a abrangência do Parque é notável quando os entrevistados relatam quais palavras estavam diretamente relacionadas ao tema: os alunos em sua maioria associaram a Serra do Periperi com o Poço Escuro e o Cristo, porém raramente marcaram o CETAS e Anel de Contorno que também estão dentro da UC. Ou seja, a tendência de absorver apenas parte da informação é bastante notória. Ainda foi possível observar que as pessoas que optaram por marcar apenas uma opção nessa questão, marcaram apenas o Poço Escuro, podendo inferir que acreditam que o Parque está restrito apenas a área da Reserva do Poço Escuro.

Outro ponto que deve ser pensado é como as informações devem ser veiculadas de modo a educar e consolidar uma informação para o público que a recebe. Durante o período da pesquisa, ocorreu em uma das escolas (Monteiro Lobato) o lançamento da revista Ecokids, do mês de outubro de 2018, participaram alunos do $5^{\circ}$ ano do Ensino Fundamental, 25 dias após o lançamento da revista produzida pela escola, foi aplicado o questionário aos alunos do $9^{\circ}$ ano do Ensino Fundamental, onde a maioria afirmou que tiveram acesso à informação sobre a Serra pela TV. Por que o grupo não citou a escola, se no mesmo mês houve um evento relacionado a essa questão com convite para todos da escola? O que só confirma que assuntos desse tipo não podem ser pontuais e feitos de forma não inclusiva a todos na instituição. Talvez a ações produzidas durante a elaboração da revista ficaram muito restritas ao $5^{\circ}$ ano e como o lançamento da Revista (que foi aberto a todos e todas da escola) ocorreu no campus da UFBA (portanto fora e distante) a maioria dos alunos não participou. Também pode ocorrer que os alunos do 9o ouviram falar do projeto, mas não reconheceram que uma atividade como essa também era algum tipo de informação. Todavia não se pode deixar de pensar que a execução do projeto e o lançamento foi algo pontual ou superficial e não atingiu a todos na escola. Este exemplo foi bastante emblemático para o nosso grupo de pesquisa e levanta questões que devem ser pensadas quando o tema é Educação Ambiental.

Segundo Medeiros et al. (2011) a escola procura transmitir para os educandos de maneira isolada e fragmentada um conhecimento pronto sobre 0 meio ambiente e suas questões, onde o modo como a Educação Ambiental é praticada nessas escolas, é apenas como projeto especial, extracurricular, sem continuidade, descontextualizado, fragmentado e desarticulado, não há efetivamente 0 desenvolvimento de uma prática educativa que integre disciplinas.

Nesse sentido, os projetos pedagógicos das escolas precisam contemplar ações e projetos que, de maneira criativa e responsável, abarquem essas premissas em suas orientações. Iniciativas que promovam a troca sadia de saberes entre o educador e o educando precisam ser valorizadas (SANTANA, 2013).

Em um comparativo das instituições em relação a proximidade geográfica do Parque e número de pessoas que já visitaram a UC, dentre as 
quatro estudadas (Figura 1), a Escola Professora Ridalva é a mais próxima e teve o menor número de alunos que visitaram o local. $O$ que reforça a necessidade da inclusão da população em programas de Educação Ambiental e popularização, como cita Oliveira et al. (2016):

[...] principalmente em escolas adjacentes a UC, promoção de Educação Ambiental com mutirões de estudantes das escolas locais juntos a população para recolhimento dos resíduos descartados na UC auxiliado pelo órgão de limpeza pública. A presença dos estudantes configura um ato educativo e um meio de sensibilização e promoção de conscientização na população local.

Sobre a falta de associação dos alunos entre o anel viário e o Parque podemos entender que devido ao fato de não haver placas em nenhum local dos limites do Parque indicando onde inicia e onde termina a UC a comunidade de fato não tem noção quais áreas do município fazem parte do Parque. Uma cartilha (Figura 8) foi produzida pela ViaBahia (concessionária de Rodovias S.A., empresa que administra desde outubro de 2009 o trecho da BR 324 - Rodovia Eng. Vasco Filho entre Salvador e Feira de Santana e o trecho da BR 116 Rodovia Santos Dumont entre Feira de Santana até a divisa com o estado de Minas Gerais) em parceria com a Prefeitura Municipal de Vitória da Conquista, onde conta histórias relacionadas a preservação do Poço Escuro bem como a fauna e flora do Parque, além disso há ainda jogos e dicas sobre conscientização ambiental. Um material rico em informações que envolvem popularização e Educação Ambiental, porém não é circulado para a população da forma como se espera.
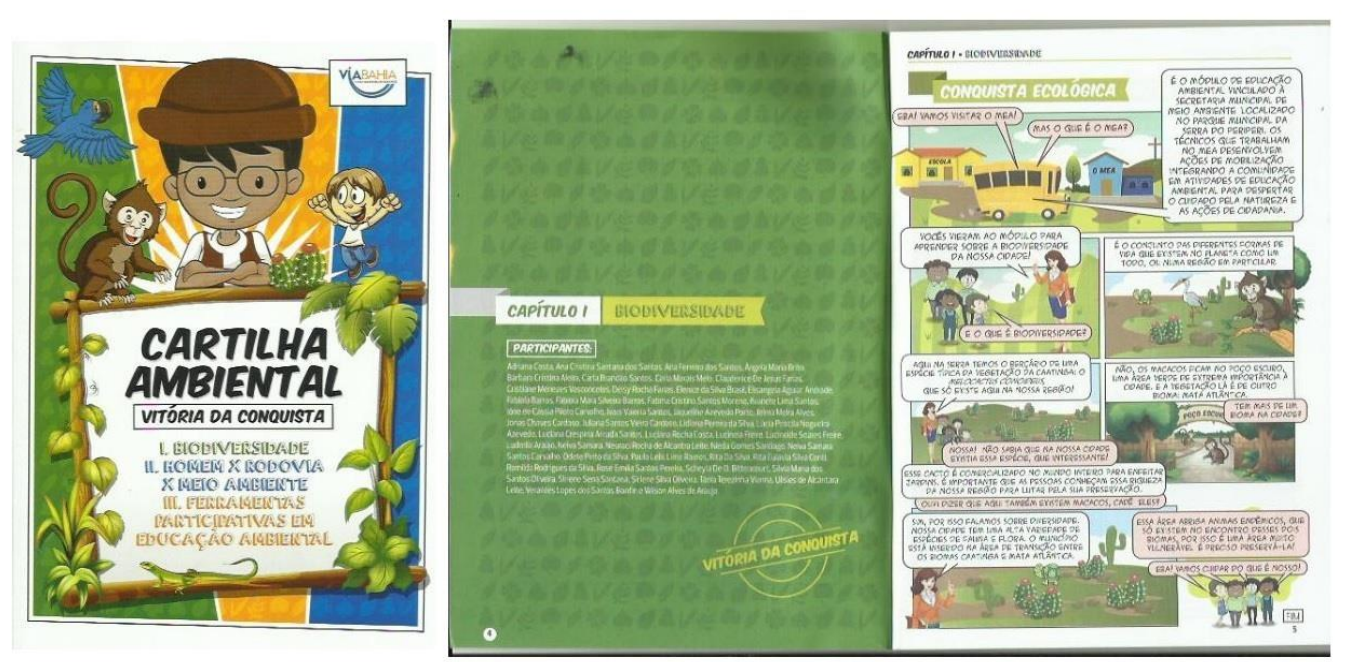

Figura 8: Cartilha Ambiental produzida pela Via Bahia em parceria com a prefeitura de Vitória da Conquista-BA. Fonte: Arquivo Pessoal. 
Diante do exposto acima, vemos a necessidade de um programa de EA efetivo para a população estudantil, principalmente. A estratégia seria a criação de algo concreto e duradouro, pois vimos que quando ocorrem projetos pontuais não há aderência e absorção do conhecimento pelos alunos. Acredita-se que a realização de Educação Ambiental tendo início na escola, poderá atingir os demais segmentos da sociedade, já que a inserção da dimensão ambiental na escola proporciona a realização de um trabalho contínuo e permanente e as transformações alcançadas, transpõem os muros da mesma (SILVA, 1995).

Dito isso, pensamos em algumas estratégias visando a melhoria da visão ambiental dessa parcela da população, como: criação de agendas anuais incluindo ações fixas e ações itinerantes tanto dos órgãos públicos responsáveis quanto das escolas/instituições de ensino; estabelecimento de calendário fixo de visitas e ações voltadas para o Parque onde toda a população contaria com o acesso guiado e protegido aos locais; inserção de propostas regulares nos currículos escolares como, por exemplo, projetos anuais em toda rede municipal; criação de um canal direto de popularização das informações importantes e necessária para a visão ambiental sobre o Parque.

A ideia é que a EA seja algo realmente construído e absorvido como ação, como afirma Silva e Leite (2008):

[...] Um dos maiores desafios é permitir que Educação Ambiental não seja trabalhada como disciplina, e sim como um processo de construção e reconstrução de conhecimento que possibilite interações com a totalidade dos conteúdos administrados nas escolas de ensino fundamental e promova mudanças de percepção, pensamentos, de atitudes e o exercício da cidadania.

A Educação Ambiental enquanto processo educativo não deve ser entendido como "disciplina isolada", mas um processo que permite ao tema meio ambiente transpor todos os conteúdos e práticas, de modo a propiciar as interações entre as várias áreas do conhecimento, de acordo com o que determina o Artigo 10ำ da Lei 9795/99 que instituiu a Política Nacional de Educação Ambiental (BRASIL, 1999).

Portanto, a percepção observada nessa pesquisa foi de bastante importância para entender a visão ambiental que o público estudantil investigado tem em relação ao Parque Municipal da Serra do Periperi. O que é confirmado por Silva et al. (2011) e França e Guimarães (2014) onde dizem que a educação e percepção ambiental surgem como armas em defesa do meio natural, e ajuda a reaproximar o homem da natureza, garantindo um futuro com mais qualidade de vida para todos, já que desperta uma maior responsabilidade e respeito dos indivíduos em relação ao ambiente em que vivem. 


\section{Considerações Finais}

Tendo em vista as informações apresentadas, vimos que um dos maiores desafios para a EA não é a falta de conhecimento sobre o assunto, mas sim maneiras mais efetivas de fazer esse conhecimento se consolidar na sociedade. Por isso os programas de formação continuada são tão importantes frente a essa temática, bem como processos de autoconscientização. Aqui vimos a existência de múltiplas publicações e materiais disponíveis para a execução da EA nas instituições de ensino.

Ao possibilitar aos alunos a oportunidade de se tornarem seres conscientes e sensibilizados a essa nova perspectiva frente ao meio ambiente, eles poderão além de melhorar sua formação, ampliar seus conhecimentos, se tornar educadores ambientais além dos muros das escolas e instituições, influenciando novas práticas e olhares em suas casas, seus círculos de amigos e sua comunidade. A popularização da ciência é de grande importância para a diminuição do analfabetismo científico na população. Porém é necessário um amparo dos órgãos públicos e instituições escolares em viabilizar ações e programas continuados, para dar apoio a esse público que deseja aprender com as ações. Programas regulares e contínuos, incluindo a EA como matéria básica nos currículos da educação básica e superior poderiam inserir de modo gradual e perene o conhecimento sobre o tema nos mais variados anos escolares.

Além disso é necessário garantir a essa parte da população, acesso à informação em linguagem adequada, contribuindo para o desenvolvimento da consciência de cada para refletir sobre as questões ambientais. E assim, refletindo sobre nossas escolas, atitudes individuais e coletivas, tanto estudantes como docentes poderão pensar em novas possibilidades para materializar a Educação Ambiental, entendendo que para as mudanças coletivas aconteçam e surtam efeito é importante mudar cada ser individualmente. A comunidade precisa além de conhecer os temas, se certificar que as mudanças são importantes e fundamentais.

\section{Agradecimentos}

Às diretoras e diretor das unidades de ensino que permitiram a realização da pesquisa, bem como demais servidores que deram o suporte necessário, aos voluntários e voluntárias que responderam aos questionários, ao Módulo de Educação Ambiental da prefeitura de Vitória da Conquista pela atenção dispensada e doação de materiais. Aos colegas da UFBA que se dispuseram a ajudar com a aplicação dos questionários, em especial Lanna Jéssica Gomes da Silva e Aline Silva Soares. Aos Drs. Alisson Cruz e Márcio B. Silva (IMS/CAT/UFBA) pelas leituras e sugestões na primeira versão desse manuscrito e a Sílvia K.A. Santos pela revisão do texto. 


\section{Referências}

AMARAL, U.T. Pressões do crescimento urbano da cidade de Vitória da Conquista sobre o Parque Municipal da Serra do Periperi. Trabalho de Conclusão de Curso (Graduação em Geografia) - Universidade Estadual do Sudoeste da Bahia, 2012.

BARBOSA, R.C.N. O papel da Educação Ambiental na escola. 2004. Disponível em:<www.santeresiduos.com.br/artigos/papel edu $>$. Acesso em: 01 dez. 2018.

BAHIA. Secretaria do Meio Ambiente. Portaria Sema no 37 de 15 de agosto de 2017. Torna pública a Lista Oficial das Espécies da Fauna Ameaçadas de Extinção do Estado da Bahia. Disponível em: < http://www.ceama.mp.ba.gov.br/biblioteca-virtual-ceama/doc view/3977portaria-n-37-de-15-de-agosto-de-2017.html>. 2017.

BEZERRA, Y. B. S. et al. Análise da percepção ambiental de estudantes do ensino fundamental II em uma escola do município de serra talhada (PE). Revista Brasileira de Educação Ambiental, v. 9, n. 2, p. 472-488, 2014.

BRASIL. Lei 9795/99. Dispõe sobre a Educação Ambiental, institui a Política Nacional de Educação Ambiental e dá outras providências. Brasília, 1999. Disponível em: http://www.planalto.gov.br/ccivil 03/leis/l9795.htm.Acesso em 11 nov. 2020.

BRASIL 2000. Lei № 9.985, de 18 de julho de 2000. Dispõe sobre o Sistema Nacional de Unidades de Conservação e dá outras providências. Disponível em: <http://www.planalto.gov.br/ccivil 03/leis/19985.htm>. Acesso em: 26 out. 2020.

COMANDULLI, C. S. Gestão territorial e ambiental de terras indígenas: fazendo planos. RURIS - Revista do Centro de Estudos Rurais. UNICAMP, v. 10, n. 1, 30 nov. 2016.

CÓRDULA, E. B. L. NASCIMENTO; G.C.C; FURTADO, G.D.; ABÍLIO, F.J.P. Educação Ambiental não formal para sensibilização do público infanto-juvenil em assentamentos na Paraíba. Revista Gaia Scientia, 9(1), 74-88, 2015.

DINCKINSON, J.L.; BONNEY, R.; Citizen science: public collaboration in environmental research. Ithaca, New York: Cornell University Press, 2012.

FERNANDES, D.N.; A importância da Educação Ambiental na construção da cidadania. Revista OKARA: Geografia em debate. João Pessoa, v.4, n.1-2, p. 77-84, 2010.

FERREIRA, M. J. M.; VIANA JÚNIOR, M. M. A expansão do agronegócio no semiárido cearense e suas implicações para a saúde, 0 trabalho e 0 ambiente. Interface: Comunicação, Saúde, Educação, v. 20, n. 58, p. 649-660, 2016. 
FRANÇA, P.A.R.; GUIMARÃES, M.G.V.; A Educação Ambiental nas Escolas Municipais de Manaus (AM): um estudo de caso a partir da percepção dos discentes. Revista do Centro do Ciências Naturais e Exatas - UFSM, Santa Maria. Revista Monografias Ambientais - REMOA, v.14, n. 2, p. 3128 - 3138, mar. 2014.

FREY, K. A dimensão político-democrática nas teorias de desenvolvimento sustentável e suas implicações para a gestão local. Ambient. soc., Campinas, n. 9, p. 115-148, dez. 2001.

GIL, A.C. Como elaborar projetos de pesquisa. 4. ed. São Paulo: Atlas, 2002.

GUIMARÃES, M. A dimensão ambiental na educação. 5. ed. Campinas: Papirus, 1995.

IVANISSEVICH, A. Uma missão de divulgar ciência no Brasil. Cienc. Culto. São Paulo, v. 61, n. 1, p. 4-5, 2009.

JACOBI, P. Educação Ambiental, cidadania e sustentabilidade. Cad. Pesqui., São Paulo, n. 118, p. 189-206, Mar. 2003.

JORDAN, R.C., GRAY, S.A., HOWE, D.V., BROOKS, W.R., EHRENFELD, J.G. Knowledge Gain and Behavioral Change in Citizen-Science Programs. Conservation Biology, v.25 n.6, p.1148-1154, 2011.

LIMA, W. Fórum Crítico da Educação. V. 3 - № 2 - Abril/05. Educação: Revista do ISEP/Programa de Mestrado em Ciências Pedagógicas. v. 3, n. 1, out. 2004.

MUELLER, S. P. M. Popularização do conhecimento científico. Revista de Ciência da Informação, v. 3, n. 2, abr. 2002.

OLIVEIRA, M.J.; PORTELA, E.P.; BARROS, J.S.; MENEZES, L.B.; SILVA, M.F.L. O convívio da cidade de Vitória da Conquista com o Parque Municipal da Serra do Periperi: o retrato atual da degradação. Anais do XIII Congresso Nacional de Meio Ambiente. Poços de Calda: UFSM, 2016.

PÁDUA, M.F.; Turismo nas Unidades de Conservação, 2010. Disponível em: $<$ https://www.oeco.org.br/colunas/maria-tereza-jorge-padua/24532-turismo-nasunidades-de-conservacao/> Acesso em: 04 de dez. 2018.

ROCHA, A.A. Análise Socioambiental da bacia do Rio Verruga os Processos da Urbanização de Vitória da Conquista - Ba. Dissertação (Mestrado em Geografia) - Curso de Pós-Graduação em Geografia, Universidade Federal da Paraíba, 2008.

SANTOS, E.T.A.; Educação Ambiental na escola: conscientização da necessidade de proteção da camada de ozônio. 2007. Trabalho de Conclusão de Curso. (Especialização em Educação Ambiental) - Universidade Federal de Santa Maria, Santa Maria, 2007. 
SANTOS, M.A.S.; SCHETTINO, S.C.; BASTOS, I.A.H.; Educação Ambiental em Unidades de Conservação: o caso da área de proteção do Morro do Urubu. Revista do Grupo de Pesquisa. Processos Identitários e Poder - GEPPIP. v. 01, n. 1, 2013.

MEDEIROS, A.B.; MENDONÇA, M.J.S.L.; SOUSA, G.L.; OLIVEIRA, I.P. A Importância da Educação Ambiental na escola nas séries iniciais. Revista Eletrônica Faculdade Montes Belos, v. 4, n. 1, 2011.

SANTANA, P.M.C; Projetos de Educação Ambiental na rede municipal de ensino de Mogi Mirim: desafios a prática pedagógica. Dissertação (Mestrado em Tecnologia), Universidade Estadual de Campinas, Faculdade de Tecnologia, 2013.

SILVA, M.M.P.S.; LEITE, V.D.; Estratégias para realização de Educação Ambiental em escolas do ensino fundamental, Revista eletrônica Mestrado Educação Ambiental, v. 20, janeiro a junho de 2008.

SILVA, M. Educação Ambiental integrada a coleta seletiva de lixo. Monografia (Especialização em Educação Ambiental), Universidade Estadual da Paraíba, Campina Grande, 1995, 95p.

SILVA, I. S. da. A Serra do Periperi e as Implicações Socioambientais Decorrente da Expansão Urbana de Vitória da Conquista- Ba. Dissertação (Mestrado em Geografia), Universidade Federal de Sergipe, 2013.

SOUZA, C.E.; SOUZA, T.A.; SOUZA, M.F. Dificuldades e motivações para a inserção da Educação Ambiental em escolas públicas situadas no entorno de uma unidade de conservação. Capítulo 8, p. 160-180. In: SOUZA, M.F; BRAZ, R.F.S. (org.) Escolas sustentáveis [recurso eletrônico]: reflexões e ações, v.1. Natal, RN: EDUFRN, 2019.

SOUSA, R. de L. Ciência na rede: popularização da ciência no canal Nerdologia. Dissertação (Mestrado em Ciências da Comunicação) - Universidade Federal do Amazonas, Manaus, 2019.

VITÓRIA DA CONQUISTA, Prefeitura Municipal de. Decreto no 9.480/99. Cria Parque Municipal da Serra do Periperi. Vitória da Conquista, 1999.

VITÓRIA DA CONQUISTA, Prefeitura Municipal de. Plano de Manejo do Parque da Serra do Periperi. Vitória da Conquista, 2017.

XAVIER, A. L. S.; SILVA, E.; ALMEIDA, E. P. O. Influência da Educação Ambiental na percepção de alunos do ensino público de Pombal, Paraíba, quanto a gestão dos resíduos sólidos. Revista Espacios (Caracas). v. 37, n. 8, p. 1, 2016. 


\section{Anexo 1}

Questionário

Idade:

Sexo: ( ) Feminino ( ) Masculino ( ) Outro Série/curso:

1. Há quantos anos mora ou estuda em Vitória da Conquista?

( ) 1 a 3 anos

( ) 4 a 6 anos

( ) +10 anos

2. Você já ouviu falar no Parque Municipal da Serra do Periperi?

( ) Sim

( ) Não

3. Como soube ou ouviu algo a respeito do Parque?

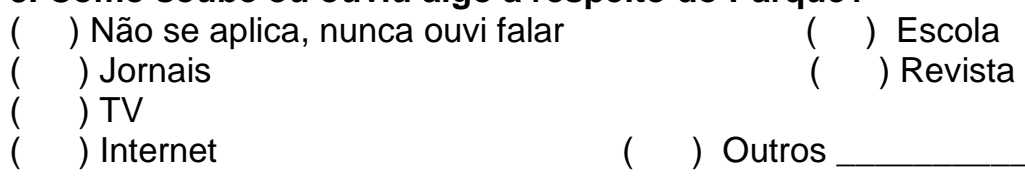

4. Você já realizou algum trabalho a respeito desse assunto?

( ) Não ( ) Não se aplica

( ) Sim, foi uma atividade que ocorreu: ( ) uma vez ( ) sempre

5. Já visitou algum local do Parque?

( ) Sim ( ) Não

6. Quais dessas palavras você acha que estão diretamente relacionadas ao Parque do Periperi?
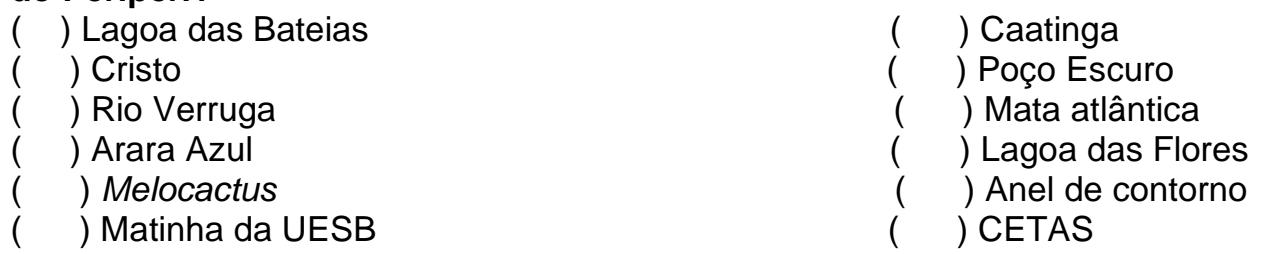

7. Algum representante da Prefeitura ou pesquisador já veio falar com você sobre o Parque do Periperi?

( ) Sim ( ) Não

8. Você já viu algum grupo ou outro órgão falando sobre o Parque do Periperi?

( ) Não. ( ) Sim.

Qual?

( ) Sim, mas não sei ou não lembro o nome.

9.Você acha que conhecer informações sobre o Parque ajuda a proteger a natureza da nossa cidade?

( ) Sim ( ) Não

10. Você gostaria de fazer parte de algum projeto para conhecer e ajudar proteger 0 Parque do Periperi?

( ) Sim ( ) Não ( ) talvez, depende do projeto.

11. Você já ouviu falar de problemas que existem no Parque Municipal?

( ) Não ( ) Sim, mas não lembro o que foi ( ) Sim. Ouvi algo sobre

12. Você acha que existe no Parque da Serra do Periperi alguma espécie correndo risco de extinção?

( ) Sim ( ) Não 